\title{
Thyroid Dysfunction in Non-Interferon Treated Hepatitis C Patients Residing in Hepatitis Endemic Area
}

\author{
Nayab Batool, ${ }^{1}$ Shan Elahi, ${ }^{2}$ Nazish Saleem, ${ }^{1}$ and Abrar Ashraf ${ }^{1}$ \\ ${ }^{1}$ Institute of Chemistry, New Campus, University of the Punjab, Lahore, Pakistan \\ ${ }^{2}$ Centre for Nuclear Medicine (CENUM), P.O. Box No. 53, Mayo Hospital, Lahore, Pakistan \\ Correspondence should be addressed to Nayab Batool; nayab.rizvi@gmail.com
}

Received 15 November 2016; Revised 20 April 2017; Accepted 26 April 2017; Published 30 May 2017

Academic Editor: Yujiang Fang

Copyright (c) 2017 Nayab Batool et al. This is an open access article distributed under the Creative Commons Attribution License, which permits unrestricted use, distribution, and reproduction in any medium, provided the original work is properly cited.

\begin{abstract}
Background. Association of thyroid dysfunction (TD) with interferon treatment of HCV is well known to clinicians. However, a few studies have highlighted the role of hepatitis $\mathrm{C}$ virus per se in the development of TD. The aim of this study was to know the prevalence of TD in non-interferon treated HCV infected patients referred for thyroid function testing. Patients and Methods. Among 557 ELISA-positive HCV patients 446 (341 females, 105 males) were selected for this study. Serums $\mathrm{FT}_{4}$, $\mathrm{FT}_{3}$, and TSH were determined by radioimmunoassay method. Results. TD was detected in 15.2\% of patients: 9.0\% hypothyroidism and $6.3 \%$ hyperthyroidism. In increasing order subclinical hypothyroidism, overt hypothyroidism, overt hyperthyroidism, and subclinical hyperthyroidism were found in $4.7 \%, 4.3 \%, 3.6 \%$, and $2.7 \%$ patients, respectively. Overall TD was more common in female than in male HCV patients but the difference was not significant ( $16.1 \%$ versus $12.4 \% ; p=0.648)$. Hyperthyroidism and subclinical hypothyroidism were slightly more common in female and overall hypothyroidism and overt hypothyroidism in male patients but the difference was not statistically significant $(p>0.05)$. The incidence of TD was relatively high in patients above 36 years (median age) but the difference was not statistically significant either collectively or in gender base groups $(p>0.05)$. Conclusion. Prior to interferon treatment, HCV infection itself causes biochemical thyroid dysfunction in $15.2 \%$ of local HCV patients.
\end{abstract}

\section{Introduction}

Hepatitis C, caused by hepatitis C virus (HCV), is a global health problem. According to the World Health Organization 3 to 4 million people are newly infected with HCV every year and there are about 180 million patients infected with $\mathrm{HCV}$ in the world [1]. In addition to hepatic complications, chronic HCV infection has been suggested to cause extrahepatic disorders [2]. These include hematologic diseases, lymphoproliferative disorders, renal disease, and endocrine diseases. The most frequent and clinically important endocrine diseases are autoimmune thyroid disorders [1-3], reported to develop in $5 \%-10 \%$ of pre- and postinterferon alpha (IFN- $\alpha$ ) treated HCV patients $[4,5]$. A significant number of chronic hepatitis $\mathrm{C}$ patients have been reported to develop biochemical thyroid dysfunction (TD; hyperthyroidism and hypothyroidism) before IFN- $\alpha$ treatment [6-8]. The potential mechanism proposed for this phenomenon is either direct effect of HCV on thyroid cells, triggering of thyroid autoimmunity by altering immune responsiveness, or both [9]. Recently it is reported that HCV can infect human thyroid cell in vitro [10] and has been detected in thyroid tissue from patients with chronic HCV infection [11].

Pakistan is second after Egypt where prevalence of hepatitis $\mathrm{C}$ is alarmingly high. Currently about 10 million people in Pakistan are infected with HCV infection [4]. A large proportion of patients with $\mathrm{HCV}$ infection have received interferon injections for its treatment. Thyroid dysfunction after interferon treatment of hepatitis $\mathrm{C}$ patients is reported in a number of local studies $[4,12,13]$ but only a few studies have determined their prevalence before starting the interferon therapy $[14,15]$. Recently we have found that one-fourth of local untreated HCV patients are TPO-Ab positive and are at greater risk of developing thyroid disorders during and after interferon treatment [16]. Keeping these facts in view this study is planned to know prevalence of TD in local HCV patients before interferon therapy. 
TABLE 1: Mean $( \pm \mathrm{SD})$ level of $\mathrm{FT}_{4}$ and TSH in subgroups of HCV patients.

\begin{tabular}{lccc}
\hline Subgroup & No. & $\mathrm{FT}_{4}(\mathrm{pmol} / \mathrm{L})$ & TSH $(\mathrm{mIU} / \mathrm{L})$ \\
\hline Euthyroid & 378 & $15.6 \pm 1.8$ & $1.7 \pm 0.8$ \\
Hypothyroid & 40 & $11.5 \pm 6.0^{\mathrm{a}}$ & $19.6 \pm 18.5^{\mathrm{b}}$ \\
Hyperthyroid & 28 & $31.4 \pm 19.1^{\mathrm{b}}$ & $0.08 \pm 0.07^{\mathrm{a}}$ \\
\hline
\end{tabular}

$\mathrm{FT}_{4}=$ free thyroxine, $\mathrm{TSH}=$ thyroid stimulating hormone, supersuffix $\mathrm{a}=$ significantly lower than euthyroid patients $(p<0.001)$, and supersuffix $\mathrm{b}=$ significantly higher than euthyroid patients $(p<0.001)$.

TABLE 2: Distribution TD in male and female HCV infected patients.

\begin{tabular}{|c|c|c|c|c|}
\hline $\mathrm{TD}$ & $\begin{array}{c}\text { Total } \\
(n=446)\end{array}$ & $\begin{array}{c}\text { Female } \\
(n=341)\end{array}$ & $\begin{array}{c}\text { Male } \\
(n=105)\end{array}$ & $p$ value \\
\hline Hypothyroidism & $40(9.0 \%)$ & $30(8.8 \%)$ & $10(9.5 \%)$ & 0.972 \\
\hline Overt & $19(4.3 \%)$ & $13(3.8 \%)$ & $06(5.7 \%)$ & 0.710 \\
\hline Subclinical & $21(4.7 \%)$ & $17(5.0 \%)$ & $04(3.8 \%)$ & 0.893 \\
\hline Hyperthyroidism & $28(6.3 \%)$ & $25(7.3 \%)$ & $03(2.9 \%)$ & 0.254 \\
\hline Overt & $16(3.6 \%)$ & $14(4.1 \%)$ & $02(1.9 \%)$ & 0.559 \\
\hline Subclinical & $12(12.7 \%)$ & $11(3.2 \%)$ & $01(0.9 \%)$ & 0.460 \\
\hline Overall TD & $68(15.2 \%)$ & $55(16.1 \%)$ & $13(12.4 \%)$ & 0.648 \\
\hline
\end{tabular}

\section{Patients and Methods}

History and laboratory records of all HCV ELISA-positive patients referred for thyroid testing to CENUM, Mayo Hospital, during January 2013 to December 2014 were reviewed. Among them such patients who were already diagnosed for thyroid diseases and taking thyroid medications or had thyroid surgery were excluded. Similarly HCV patients previously treated with interferon were also excluded. We selected those patients whose serum samples were analyzed for both $\mathrm{FT}_{4}$ and TSH concentrations with or without $\mathrm{FT}_{3}$ determination. In these patients serums $\mathrm{FT}_{4}$ and $\mathrm{FT}_{3}$ were determined by radioimmunoassay (RIA) and TSH was estimated by IRMA techniques using commercial kits of Immunotech Inc. (Beckman, Czech Republic). RIA and IRMA batches were run with commercially derived control sera at low, medium, and high concentrations which were included in every run. All assays were carried out in duplicate. Measurement of radioactivity, fitting of the standard curve, and analysis of samples were carried out using a computerized gamma counter (Cap-RIA 16, CAPINTEC Inc., USA). RIA and IRMA results were expressed at less than $10 \% \mathrm{CV}$ of imprecision profile.

Normal ranges for $\mathrm{FT}_{4}, \mathrm{FT}_{3}$, and TSH, as standardized in our laboratory, are $11.0-22.0 \mathrm{pmol} / \mathrm{L}, 2.5-5.8 \mathrm{pmol} / \mathrm{L}$, and 0.3-4.0 mIU/L, respectively. Hyperthyroidism was classified if serum TSH was $\leq 0.1 \mathrm{mIU} / \mathrm{L}$ and $\mathrm{FT}_{4}>22.0 \mathrm{pmol} / \mathrm{L}$ and as subclinical if serum TSH was $\leq 0.1 \mathrm{mIU} / \mathrm{L}$ and $\mathrm{FT}_{4} \leq$ $22.0 \mathrm{pmol} / \mathrm{L}$. Hypothyroidism was considered as overt if TSH $>4.0 \mathrm{mIU} / \mathrm{L}$ and $\mathrm{FT}_{4}<11.0 \mathrm{pmol} / \mathrm{L}$ and as subclinical if TSH $>4.0 \mathrm{mIU} / \mathrm{L}$ and $\mathrm{FT}_{4} \geq 11.0 \mathrm{pmol} / \mathrm{L}$. The analysis of data was carried out using Microsoft Excel program on a personal computer. Chi-square and Student $t$-test were applied to test the significance of difference between two arbitrary groups. A $p$ value of less than 0.05 was considered significant.

\section{Results}

Among 557 ELISA-positive newly diagnosed HCV patients 446 were selected for this study. The remaining patients were excluded either due to determination of TSH alone $(n=$ $107)$ or due to combination of $\mathrm{FT}_{3}$ and TSH $(n=4)$. In selected patients both serums $\mathrm{FT}_{4}$ and TSH were determined with or without additional determination of $\mathrm{FT}_{3}$. As serum $\mathrm{FT}_{3}$ was determined in only $95(21.3 \%)$ patients we excluded this parameter from data analysis. Among selected patients 341 were female and 105 male patients. Their mean $( \pm S D)$ age was $37.1 \pm 11.1$ years with age range between 10 and 90 years and was comparable in male and female patients $(35.8 \pm 11.6$ versus $37.5 \pm 11.9 ; p=0.198)$. Analysis of thyroid function tests showed that 378 (84.7\%) patients had serum TSH level within normal range $(0.3-4.0 \mathrm{mIU} / \mathrm{L})$ and were euthyroid. Among the rest of the patients with abnormal TSH $(n=68 ; 15.3 \%), 40$ (9.0\%) had hypothyroidism and 28 (6.3\%) had hyperthyroidism. Further subgrouping of HCV patients having thyroid disorder revealed that, in increasing order, $21(4.7 \%)$ patients had subclinical hypothyroidism, 19 $(4.3 \%)$ patients had overt hypothyroidism, 16 (3.6\%) patients had overt hyperthyroidism, and $12(2.7 \%)$ had subclinical hyperthyroidism. Table 1 shows the mean $( \pm \mathrm{SD})$ level of $\mathrm{FT}_{4}$ and TSH in euthyroid, hypothyroid, and hyperthyroid HCV patients. Compared to euthyroid patients serum $\mathrm{FT}_{4}$ concentration was significantly lower in hypothyroid and higher in hyperthyroid patients (both $p<0.001$ ). Likewise serum TSH concentration was significantly higher in hypothyroid and lower in hyperthyroid as compared to euthyroid HCV patients.

The gender base difference in incidence of TD is elaborated in Table 2. Overall TD was more common in female than in male HCV patients but the difference was not significant (16.1\% versus $12.4 \% ; p=0.648$ ). Hyperthyroidism (overt 
TABLE 3: Effect of patient age on incidence of thyroid dysfunction in HCV infected patients.

\begin{tabular}{ll}
\hline Age group & TD \\
\hline All patients & \\
$\quad \leq 36.0$ year $(n=232)$ & $27(11.6 \%)$ \\
$\quad>36.0$ year $(n=214)$ & $41(19.2 \%)$ \\
Female & $22(12.6 \%)$ \\
$\quad \leq 36.0$ year $(n=175)$ & $33(19.9 \%)$ \\
$\quad>36.0$ year $(n=166)$ & \\
Male & $05(08.8 \%)$ \\
$\quad \leq 36.0$ year $(n=57)$ & $08(16.7 \%)$ \\
$\quad>36.0$ year $(n=48)$ & 0.189 \\
\hline
\end{tabular}

and subclinical) and subclinical hypothyroidism was slightly more common in female as compared to male HCV patients. However, in none of them was the difference statistically significant. Only overall hypothyroidism and overt hypothyroidism were more frequent in male HCV patients but the difference was not statistically significant $(p>0.05)$. Thyroid swelling was detected in $19(5.6 \%)$ patients and all of them were females. The incidence of TD was significantly higher in these women as compared to those women presenting without goiter $(36.8 \%$ versus $14.9 \%$; $p=0.044)$. Seven among them had TD (two hypothyroidism, five hyperthyroidism). However, excluding these goitrous women from analysis slightly reduced the incidences of hypothyroidism $(8.8 \%$ to $8.7 \%)$ as well as hyperthyroidism (7.3\% to $6.2 \%)$ but statistical difference remained comparable $(p>0.05)$ between female and male HCV positive counterparts.

The age range in our patients was 10-90 years and the median age was 36 years. To elucidate the role of patient age in incidence of TD, patients were divided on the basis of median age. Table 3 shows the incidence of TD in HCV patients grouped according to median age. The incidence of TD was relatively high in patients above 36 years of age but the difference was not statistically significant $(p>0.05)$ either collectively or in gender base groups.

\section{Discussion}

The aim of this study was to know the prevalence of thyroid dysfunction in interferon-naive $\mathrm{HCV}$ patients referred to CENUM, Mayo Hospital, for thyroid function testing. Our results showed that thyroid dysfunction was detected in $15.2 \%$ of the HCV patients. This figure is in accordance with studies carried out in other countries reporting thyroid dysfunction in $7 \%$ to $15 \%$ untreated $\mathrm{HCV}$ patients $[6-8,17]$. A recent review of such studies reported $10-15 \%$ frequency of TD in interferon-free HCV patients [18]. This high incidence of TD is supported by our previous finding of a high incidence of TPO-Ab (26.8\%) in such patients [16]. Local studies carried out in other cities of Pakistan have reported incidence of TD ranging from $7 \%$ to $22 \%$ in $\mathrm{HCV}$ patients before interferon treatment $[2,14,15]$. However, our patient selection method was different from these studies. Unlike these investigations that enrolled consecutively all HCV patients we included only those HCV patients suspected of thyroid dysfunction and hence referred to our Centre for thyroid function testing.

The prevalence of TD in general population is around $5 \%$ with more incidence of hypothyroidism compared to hyperthyroidism $[19,20]$. According to our results, though overall incidence of TD was much higher than general population, pattern of relatively more hypothyroidism $(9.0 \%)$ than hyperthyroidism (6.3\%) was observed in HCV patients. This result is in accordance with other studies in which higher incidence of hypothyroidism as compared to hyperthyroidism is reported in HCV patients [15, 17]. According to a recent meta-analysis $\mathrm{HCV}$ patients are three times more prone to hypothyroidism as compared to control subjects [21]. Keeping in view a high incidence of TPO-Ab in local $\mathrm{HCV}$ patients it is expected that this hypothyroidism is probably autoimmune in origin [22]. However, conformation is necessary as nonautoimmune hypothyroidism is also reported in HCV infection [23].

Most studies have reported higher incidence of TD in female HCV patients as compared to male patients because of high incidence of thyroid autoimmunity in female patients $[24,25]$. In this study female $\mathrm{HCV}$ patients have higher incidence of TD as compared to male patients (16.1\% versus $12.4 \%$ ) but difference was not significant. This observation is similar to a local study [2] and is supported by our previous finding of comparable incidence of TPO-Ab in male and female HCV patients [16]. Although a nonsignificant gender difference of TD incidence is also reported by other studies $[26,27]$, most plausible reason seems to be low number of male patients (less than one-third of female patients) included in this study. Increasing number of male patients might decrease the percentage of TD in them to a significant level. A previous Chinese study had reported more incidence of TD in female patient even if male patients outnumbered the females [28]. A novel observation in this study was the neck swelling (goiter) detected only in female HCV patients. We found no study in literature to compare this finding. Similarly association of goiter with TD in HCV infected female patients is not reported in any study.

We also investigated incidence of TD in HCV patients of different age groups. It was observed that incidence of thyroid dysfunction was relatively high in patients above 36 years of age but was not statistically more as compared to 
younger patients. This was true for both male and female HCV patients. This finding is supported by other studies $[26,27]$ that found no increasing trend of TD with increasing age in $\mathrm{HCV}$ patients.

Limitations of this study are its cross-sectional nature, comparatively low number of male patients, serum $\mathrm{FT}_{3}$ determination in a few patients, and incomplete medical information like liver enzyme and biopsy status. Recently an association between liver dysfunction and thyroid hormone has been elucidated in HCV patients [28-30]. Besides these we have not determined thyroid autoimmunity related parameters like serums Tg-Ab and TPO-Ab and ultrasound echogenicity in our patients.

In conclusion $\mathrm{HCV}$ infection, independent of interferon treatment itself causes biochemical thyroid dysfunction in $15.2 \%$ of local patients without age and gender consideration. In Pakistan, local studies have reported TD in $20 \%$ of HCV patients after IFN-alpha and ribavirin treatment $[13,31]$. It may be speculated that this high incidence is because of preexisting TD in these patients. Thus pretreatment screening is recommended for all $\mathrm{HCV}$ patients in whom IFN- $\alpha$ therapy is being planned. Thyroid disease need not be a contraindication to IFN- $\alpha$ therapy; early detection of subclinical or overt thyroid disease may allow uninterrupted continuation of IFN- $\alpha$ treatment. However, periodic monitoring of TD patients should be performed during therapy.

\section{Conflicts of Interest}

The authors have no conflicts of financial interest.

\section{References}

[1] Y. Waheed, U. Saeed, S. Anjum, M. S. Afzal, and M. Ashraf, "Development of global consensus sequence and analysis of highly conserved domains of the HCV NS5B protein," Hepatitis Monthly, vol. 12, no. 9, Article ID e6142, 2012.

[2] M. K. Shaikh, J. A. Samo, B. R. Devrajani, and S. Z. A. Shah, "Extra hepatic manifestations of patients with chronic hepatitis C," World Applied Sciences Journal, vol. 20, no. 6, pp. 812-817, 2012.

[3] Y. Tomer, "Hepatitis C and interferon induced thyroiditis," Journal of Autoimmunity, vol. 34, no. 3, pp. J322-J326, 2010.

[4] Y. Waheed, "Effect of interferon plus ribavirin therapy on hepatitis $C$ virus genotype 3 patients from Pakistan: treatment response, side effects and future prospective," Asian Pacific Journal of Tropical Medicine, vol. 8, no. 2, pp. 85-89, 2015.

[5] D. L. Ward and R. G. Bing-You, "Autoimmune thyroid dysfunction induced by interferon-alfa treatment for chronic hepatitis $\mathrm{C}$ : screening and monitoring recommendations," Endocrine Practice, vol. 7, no. 1, pp. 52-58, 2001.

[6] M. Marazuela, L. García-Buey, B. González-Fernández et al., "Thyroid autoimmune disorders in patients with chronic hepatitis C before and during interferon- $\alpha$ therapy," Clinical Endocrinology, vol. 44, no. 6, pp. 635-642, 1996.

[7] N. Ganne-Carrie, A. Medini, E. Coderc et al., "Latent autoimmune thyroiditis in untreated patients with HCV chronic hepatitis: a case-control study," Journal of Autoimmunity, vol. 14, no. 2, pp. 189-193, 2000.
[8] D. V. Stefanova-Petrova, A. H. Tzvetanska, E. J. Naumova et al., "Chronic hepatitis $\mathrm{C}$ virus infection: prevalence of extrahepatic manifestations and association with cryoglobulinemia in Bulgarian patients," World Journal of Gastroenterology, vol. 13, no. 48, pp. 6518-6528, 2007.

[9] N. Akeno, J. T. Blackard, and Y. Tomer, "HCV E2 protein binds directly to thyroid cells and induces IL-8 production: a new mechanism for HCV induced thyroid autoimmunity," Journal of Autoimmunity, vol. 31, no. 4, pp. 339-344, 2008.

[10] J. T. Blackard, L. Kong, A. K. Huber, and Y. Tomer, "Hepatitis C virus infection of a thyroid cell line: implications for pathogenesis of hepatitis C virus and thyroiditis," Thyroid, vol. 23, no. 7, pp. 863-870, 2013.

[11] J. Bartolomé, E. Rodríguez-Iñigo, P. Quadros et al., "Detection of hepatitis $\mathrm{C}$ virus in thyroid tissue from patients with chronic HCV infection," Journal of Medical Virology, vol. 80, no. 9, pp. 1588-1594, 2008.

[12] A. Nadeem, M. M. Hussain, M. Aslam, and T. Hussain, "Interferon-alpha induced and ribavirin induced thyroid dysfunction in patients with chronic hepatitis C," Hepatitis Monthly, vol. 10, no. 2, pp. 132-140, 2010.

[13] B. Salim, M. Khurram, S. I. Gilani, K. Ejaz, M. Arif, and H. B. Khaar, "Thyroid function abnormalities in chronic hepatitis $\mathrm{C}$ patients treated with standard interferon and ribavirin at three months after starting treatment," Pakistan Journal of Gastroenterology, vol. 22, no. 1, pp. 28-31, 2008.

[14] M. A. Saeed, M. Sadiq, A. Zulfiqar, J. Irfan, and S. Jalali, "Thyroid disorders in hepatitis C virus infected untreated patients," Journal of Rawalpindi Medical College, vol. 13, no. 2, pp. 60-62, 2009.

[15] M. Imran, K. Kammeruddin, and N. Sajid, "Frequency of thyroid dysfunction in chronic hepatitis C sero positives," Pakistan Medicine and Dentistry, vol. 5, no. 1, pp. 25-27, 2016.

[16] M. I. Shafiq, A. Gauhar, M. Akram, and S. Elahi, "Thyroid peroxidase antibodies in non-interferon treated hepatitis C patients in Pakistan," BioMed Research International, vol. 2015, Article ID 172981, 5 pages, 2015.

[17] C. Shao, N. Huo, L. Zhao et al., "The presence of thyroid peroxidase antibody of IgG2 subclass is a risk factor for thyroid dysfunction in chronic hepatitis C patients," European Journal of Endocrinology, vol. 168, no. 5, pp. 717-722, 2013.

[18] S. M. Ferrari, P. Fallahi, A. Antonelli, and S. Benvenga, "Environmental issues in thyroid diseases," Frontiers in Endocrinology, vol. 8, 2017.

[19] J. G. Hollowell, N. W. Staehling, W. Dana Flanders et al., "Serum $\mathrm{TSH}, \mathrm{T}_{4}$, and thyroid antibodies in the United States population (1988 to 1994): National Health and Nutrition Examination Survey (NHANES III)," Journal of Clinical Endocrinology and Metabolism, vol. 87, no. 2, pp. 489-499, 2002.

[20] A. Lucas, M. T. Julián, A. Cantón et al., "Undiagnosed thyroid dysfunction, thyroid antibodies, and iodine excretion in a Mediterranean population," Endocrine, vol. 38, no. 3, pp. 391396, 2010.

[21] Y. Shen, X. Wang, J. Xie et al., “Thyroid disturbance in patients with chronic hepatitis $\mathrm{C}$ infection: a systematic review and meta-analysis," Journal of Gastrointestinal and Liver Diseases, vol. 25, no. 2, pp. 227-234, 2016.

[22] L. A. Salazar, X. Garcia-Samper, R. Suarez-Carpio et al., "Hypothyroidism in noninterferon treated-HCV infected individuals is associated with abnormalities in the regulation of Th17 Cells," Hepatitis Research and Treatment, vol. 2010, Article ID 971095, 6 pages, 2010. 
[23] G. Indolfi, S. Stagi, E. Bartolini et al., "Thyroid function and anti-thyroid autoantibodies in untreated children with vertically acquired chronic hepatitis C virus infection," Clinical Endocrinology, vol. 68, no. 1, pp. 117-121, 2008.

[24] A. Testa, P. Castaldi, V. Fant et al., "Prevalence of HCV antibodies in autoimmune thyroid disease," European Review for Medical and Pharmacological Sciences, vol. 10, no. 4, pp. 183-186, 2006.

[25] H. G. Hass, R. Klein, O. Nehls, and S. Kaiser, "Thyroid disorders and occurrence of Nonorgan-Specific Autoantibodies (NOSA) in patients with chronic hepatitis $\mathrm{C}$ before and during antiviral induction therapy with consensus interferon (interferon alfacon-1)," Journal of Clinical Gastroenterology, vol. 43, no. 5, pp. 470-476, 2009.

[26] L. Muratori, D. P. Bogdanos, P. Muratori et al., "Susceptibility to thyroid disorders in hepatitis C," Clinical Gastroenterology and Hepatology, vol. 3, no. 6, pp. 595-603, 2005.

[27] M.-J. Huang, S.-L. Tsai, B.-Y. Huang, I.-S. Sheen, C.-T. Yeh, and Y.-F. Liaw, "Prevalence and significance of thyroid autoantibodies in patients with chronic hepatitis $\mathrm{C}$ virus infection: a prospective controlled study," Clinical Endocrinology, vol. 50, no. 4, pp. 503-509, 1999.

[28] X.-R. Mao, L.-T. Zhang, H. Chen, P. Xiao, and Y.-C. Zhang, "Possible factors affecting thyroid dysfunction in hepatitis C virus-infected untreated patients," Experimental and Therapeutic Medicine, vol. 8, no. 1, pp. 133-140, 2014.

[29] M. Tawfik and A. El-Sawy, "Low serum free and total triiodothyronine hormones as possible prognostic factors in liver cirrhotic patients because of chronic hepatitis C,' Tanta Medical Journal, vol. 43, no. 2, pp. 46-51, 2015.

[30] M. A. El-Feki, N. H. Abdalla, M. I. Atta, and A. A. Ibrahim, "Serum level of thyroid hormones in patients with chronic hepatitis C virus infection," Open Journal of Endocrine and Metabolic Diseases, vol. 6, no. 3, pp. 126-134, 2016.

[31] N. Masood, R. Ghori, A. Memon et al., "Frequency of thyroid disorders during interferon and ribavirin therapy in chronic hepatitis C infection," Journal of the College of Physicians and Surgeons Pakistan, vol. 18, no. 6, pp. 347-351, 2008. 


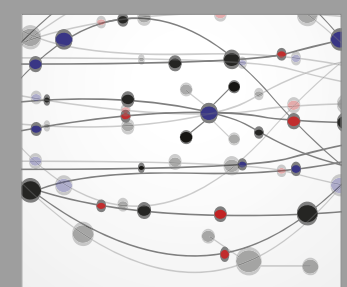

The Scientific World Journal
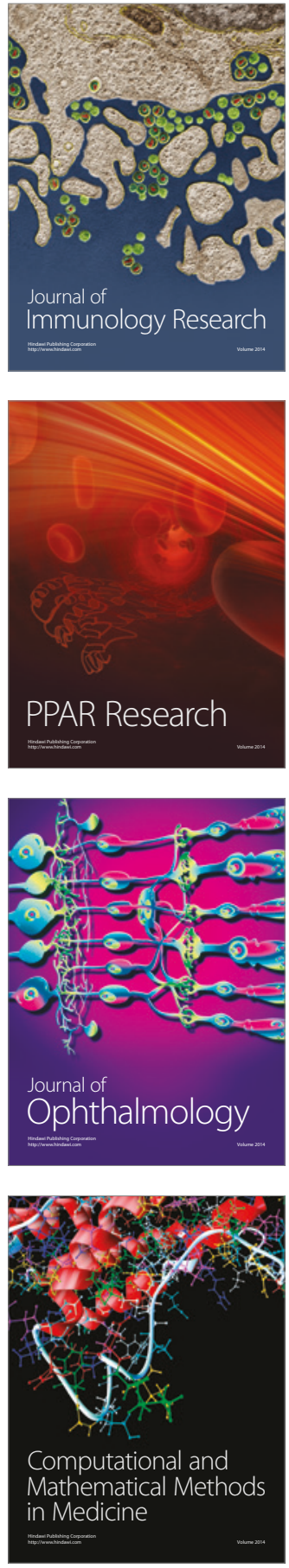

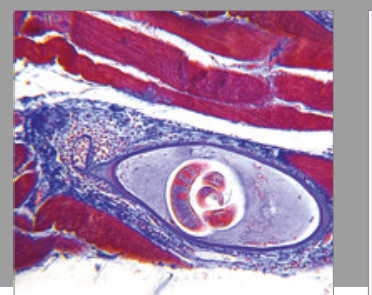

Gastroenterology Research and Practice
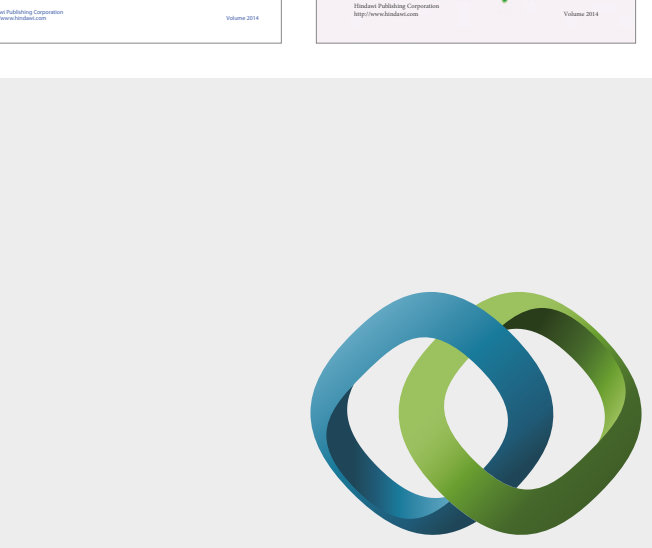

\section{Hindawi}

Submit your manuscripts at

https://www.hindawi.com
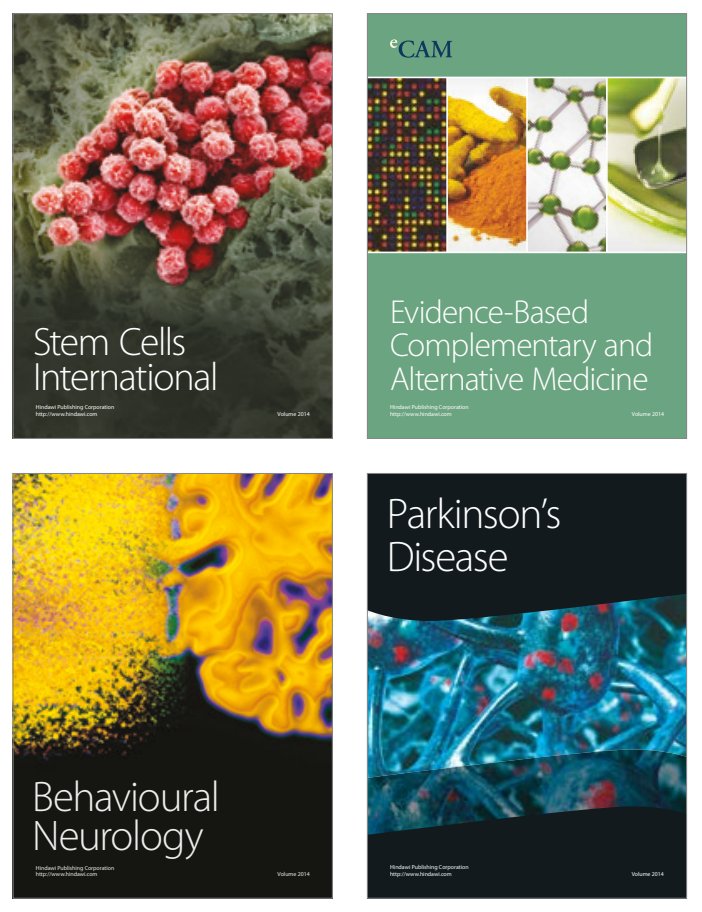
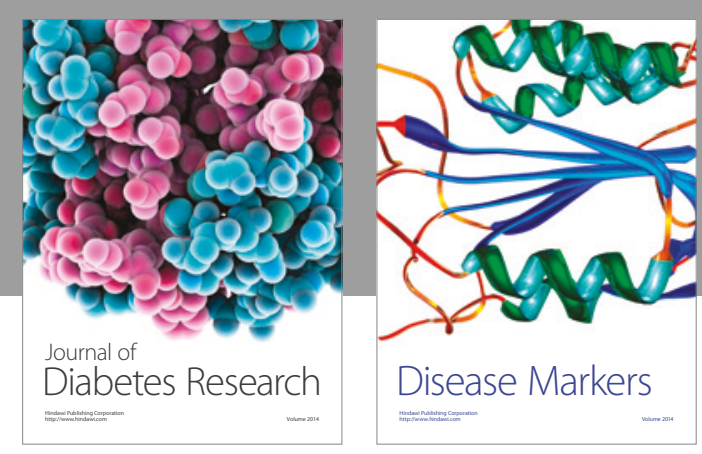

Disease Markers
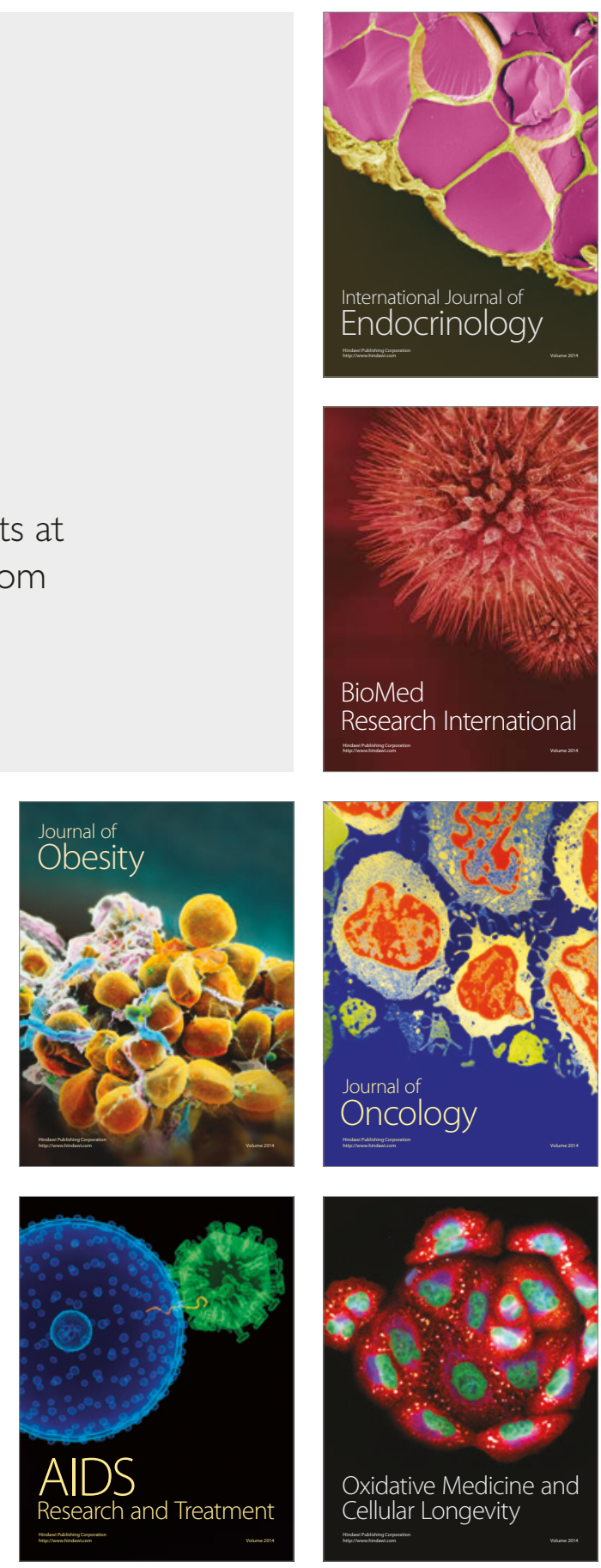